\title{
Deficiency of SUMO-specific protease 1 induces arsenic trioxide-mediated apoptosis by regulating XBP1 activity in human acute promyelocytic leukemia
}

\author{
FEI-FEI WANG ${ }^{1,2}$, MING-ZHU LIU ${ }^{2}$, YI SUI ${ }^{2}$, QING CAO $^{3}$, BO YAN ${ }^{2}$, MEI-LING JIN ${ }^{2}$ and XI MO ${ }^{1}$ \\ ${ }^{1}$ Institute for Pediatric Translational Medicine, Shanghai Children's Medical Center of Shanghai Jiao Tong University, \\ Shanghai 200127; ${ }^{2}$ Shanghai YiBeiRui Biotechnology Co., Ltd., Shanghai 201318; ${ }^{3}$ Department of Infectious Diseases, \\ Shanghai Children's Medical Center of Shanghai Jiao Tong University, Shanghai 200127, P.R. China
}

Received June 25, 2015; Accepted August 22, 2016

DOI: $10.3892 / \mathrm{ol} .2016 .5162$

\begin{abstract}
Small ubiquitin-like modifier (SUMO)/ sentrin-specific protease 1 (SENP1), a member of the SENP family, is highly expressed in several neoplastic tissues. However, the effect of SENP1 in acute promyelocytic leukemia (APL) has not been elucidated. In the present study, it was observed that SENP1 deficiency had no effect on the spontaneous apoptosis or differentiation of NB4 cells. Arsenic trioxide $\left(\mathrm{As}_{2} \mathrm{O}_{3}\right)$ could induce the upregulation of endoplasmic reticulum (ER) stress, resulting in the apoptosis of NB4 cells. Additionally, knockdown of SENP1 significantly increased $\mathrm{As}_{2} \mathrm{O}_{3}$-induced apoptosis in NB4 cells transfected with small interfering RNA targeting SENP1. SENP1 deficiency also increased the accumulation of SUMOylated $\mathrm{X}$-box binding protein 1 (XBP1), which was accompanied by the downregulation of the messenger RNA expression and transcriptional activity of the XBP1 target genes endoplasmic reticulum-localized DnaJ 4 and Sec61a, which were involved in ER stress and closely linked to the apoptosis of NB4 cells. Taken together, these results revealed that the specific de-SUMOylation activity of SENP1 for XBP1 was involved in the ER stress-mediated apoptosis caused by $\mathrm{As}_{2} \mathrm{O}_{3}$ treatment in NB4 cells, thus providing insight into potential therapeutic targets for APL treatment via manipulating XBP1 signaling during ER stress by targeting SENP1.
\end{abstract}

Correspondence to: Miss. Xi Mo, Institute for Pediatric Translational Medicine, Shanghai Children's Medical Center of Shanghai Jiao Tong University, 1678 Dongfang Street, Shanghai 200127, P.R. China

E-mail: moqkxy@126.com

Key words: SENP1, acute promyelocytic leukemia, $\mathrm{As}_{2} \mathrm{O}_{3}$, SUMOylation, XBP1, apoptosis

\section{Introduction}

Acute myeloid leukemia (AML) is composed of a group of diseases with marked morphological and cytogenetic heterogeneity that account for $20 \%$ of childhood and adolescent acute leukemias $(1,2)$. Acute promyelocytic leukemia (APL) is considered a distinct subtype of AML, with a particular cytological morphology ( $\mathrm{M}$ and $\mathrm{M} 3$ variant in the French-American-British classification) (3). APL is characterized by a specific chromosome translocation, $\mathrm{t}(15 ; 17)$, which results in the rearrangement of the promyelocytic leukemia (PML) gene and the retinoic acid receptor $\alpha(\mathrm{RAR} \alpha)$ gene, followed by the expression of the PML-RAR $\alpha$ chimeric protein (4). Despite the fact that majority of APL cases can achieve complete remission when treated with conventional chemotherapy by all-trans retinoic acid (ATRA) and/or arsenic trioxide $\left(\mathrm{As}_{2} \mathrm{O}_{3}\right)(5-8)$, certain clinical cases exhibit acquired resistance and APL relapse $(5,6,8)$, and the detailed molecular mechanisms have not been completely elucidated.

The small ubiquitin-like modifier (SUMO)/ sentrin-specific protease (SENP) family includes six SENPs named SENP1, SENP2, SENP3, SENP5, SENP6 and SENP7, which have different substrate specificities and subcellular localizations in mammalian cells (9). It has been reported that SENP1 is important in placental development and erythropoiesis $(10,11)$. In addition, SENP1 could control adipocyte differentiation via de-SUMOylation modification (12), and is important in protecting against myocardial ischemia/reperfusion injury via a hypoxia-inducible factor $1 \alpha$-dependent pathway (13). Numerous studies have demonstrated that SENP1 is overexpressed and contributes significantly to the development and progression of tumors, including prostatic intraepithelial neoplasia, colon cancer and pancreatic cancer (14-16). Previous studies have revealed that deficiency or downregulation of SENP1 could induce radiosensitization in lung cancer cells (17), promote endoplasmic reticulum (ER) stress-induced apoptosis in MEF and HEK 293T cells (18), and increase apoptosis in Burkitt lymphoma cells (19). Furthermore, SENP1 is also involved in the formation of PML protein nuclear bodies $(20,21)$, which were originally characterized as part of a fusion protein with 
PML-RAR $\alpha$ in patients with APL (22). However, whether SENP1 is a potential drug target for APL treatment still remains unclear.

ER stress has been implicated in diverse diseases, including cancer, diabetes, cerebral ischemia, and neurodegenerative and cardiovascular diseases $(23,24)$. In addition to the intrinsic and extrinsic apoptosis pathways, ER stress-induced apoptosis has recently been reported as another major pathway mediating cell apoptosis (25), and is involved in arsenic-induced apoptosis of osteoblasts, myoblasts, pancreatic cells, myeloma cells, and drug-sensitive and drug-resistant leukemia cells (26-30). It has been suggested that $\mathrm{As}_{2} \mathrm{O}_{3}$ can induce human lens cell apoptosis by the ER stress-initiated process (31).

In the present study, the NB4 cell line (an APL cell line from a relapsed APL patient) was utilized as an in vitro model (32). It was demonstrated that $\mathrm{As}_{2} \mathrm{O}_{3}$ could induce ER stress-initiated apoptosis in NB4 cells, which was significantly upregulated by SENP1 knockdown. In addition, it was observed that SENP1 specifically de-SUMOylated $\mathrm{X}$-box binding protein 1 (XBP1) and played a critical role during $\mathrm{As}_{2} \mathrm{O}_{3}$-induced ER stress. Taken together, our results revealed the roles of SENP1 in APL and the potential effects of clinical APL treatment by targeting SENP1.

\section{Materials and methods}

Antibodies and reagents. RPMI-1640 medium, Dulbecco's modified Eagle medium, trypsin and TRIzol were obtained from Invitrogen (Thermo Fisher Scientific, Inc., Waltham, MA, USA). Puromycin and fetal bovine serum (FBS) were purchased from Gibco (Thermo Fisher Scientific, Inc.). $\mathrm{As}_{2} \mathrm{O}_{3}$ was provided by Beijing Shuanglu Pharmaceutical Co., Ltd. (Beijing, China). Radioimmunoprecipitation assay lysates were purchased from Beyotime Institute of Biotechnology (Haimen, China). ATRA, phenylmethylsulfonyl fluoride, aprotinin, leupeptin and pepstatin were acquired from Sigma-Aldrich (Merck Millipore, Darmstadt, Germany). Protein A/G PLUS-Agarose was obtained from Roche Diagnostics (Indianapolis, IN, USA). Anti-XBP1 antibody (cat. no. H00007494-D01) and anti-SUMO-1 antibody (cat. no. AJ1746a) were purchased from Abnova (Taipei City, Taiwan) and Abgent Biotech Co., Ltd. (Suzhou, China), respectively. The FITC Annexin V Apoptosis Detection kit and the anti-cluster of differentiation (CD) $11 \mathrm{~b}$ antibody (cat. no. C09-550019) were commercially available from BD Pharmingen (San Diego, CA, USA). The PrimeScript RT reagent kit and SYBR Green PCR Master Mix were commercially available from Takara Bio, Inc. (Otsu, Japan).

Cell culture. Human APL NB4 cells (American Type Culture Collection, Manassas, VA, USA) were suspended at $5 \times 10^{5}$ cells $/ \mathrm{ml}$ in RPMI-1640 medium supplemented with $10 \%$ FBS. Retrovirus containing SENP1 small interfering RNA (siRNA) or nonspecific control (NC) siRNA, as described previously (10), was transfected into NB4 cells to generate si-SENP1-transfected NB4 cells (si-SENP1) or NC siRNA-transfected cells (si-NC) upon puromycin $(0.75 \mu \mathrm{g} / \mathrm{ml})$ selection. All cells were cultured in RPMI-1640 medium with $10 \% \mathrm{FBS}$ at $37^{\circ} \mathrm{C}$ in $5 \% \mathrm{CO}_{2}$.
Table I. Sequences of the primers used in the amplification of the target genes.

\begin{tabular}{|c|c|}
\hline Locus & Primers $\left(5^{\prime}-3^{\prime}\right)$ \\
\hline$\beta$-actin & $\begin{array}{l}\text { (F) CTTTTCCAGCCTTCCTTCTTGG } \\
\text { (R) CAGCACTGTGTTGGCATAGAGG }\end{array}$ \\
\hline SENP1 & $\begin{array}{l}\text { (F) ATCAGGCAGTGAAACGTTGGAC } \\
\text { (R) ATCAGGCAGTGAAACGTTGGAC }\end{array}$ \\
\hline GADD153 & $\begin{array}{l}\text { (F) GAAACGGAAACAGAGTGGTCATTCCCC } \\
\text { (R) GTGGGATTGAGGGTCACATCATTGGCA }\end{array}$ \\
\hline ATF6 & $\begin{array}{l}\text { (F) ATGAAGTTGTGTCAGAGAAC } \\
\text { (R) GGGTGCTATTGTAATGACTCA }\end{array}$ \\
\hline GRP78 & $\begin{array}{l}\text { (F) AGTTGATATTGGAGGTGGGC } \\
\text { (R) CATTGAAGTAAGCTGGTACAGTAAC }\end{array}$ \\
\hline Erdj4 & $\begin{array}{l}\text { (F) CCCCAGTGTCAAACTGTACCAG } \\
\text { (R) AGCGTTTCCAATTTTCCATAAATT }\end{array}$ \\
\hline Sec61a & $\begin{array}{l}\text { (F) CTATTTCCAGGGCTTCCGAGT } \\
\text { (R) AGGTGTTGTACTGGCCTCGGT }\end{array}$ \\
\hline Edem & $\begin{array}{l}\text { (F) AAGCCCTCTGGAACTTGCG } \\
\text { (R) AACCCAATGGCCTGTCTGG }\end{array}$ \\
\hline
\end{tabular}

F, forward; R, reverse; SENP1, Small ubiquitin-like modifier/sentrin-specific protease 1; GADD153, growth arrest and DNA damage inducible protein 153; ATF6, activating transcription factor 6; GRP78, 78 kDa glucose-regulated protein; ErdJ4,ER-localized DnaJ 4; Edem, ER degradation enhancer, mannosidase; ER, endoplasmic reticulum.

$\mathrm{As}_{2} \mathrm{O}_{3}$ and ATRA treatment. NB4 cells were seeded into a 6-well plate and then incubated with $\mathrm{As}_{2} \mathrm{O}_{3}(1 \mu \mathrm{M})$ or ATRA $(1 \mu \mathrm{M})$ for different time periods, as indicated. A total of $10^{6}$ cells were harvested at different time points subsequent to $\mathrm{As}_{2} \mathrm{O}_{3}$ or ATRA treatment.

Flow cytometry. For apoptosis assay, cells treated with $\mathrm{As}_{2} \mathrm{O}_{3}$ at each indicated time point were washed twice with ice-cold phosphate-buffered saline, and the apoptotic cells were detected with a flow cytometer (Merck Millipore) using the FITC Annexin V Apoptosis Detection kit according to the manufacturer's protocol. For CD11b assay, cells were incubated with fluorescein isothiocyanate (FITC)-conjugated anti-CD11b antibody (1:100) after treatment with ATRA for $24 \mathrm{~h}$. Appropriate isotype control IgG2b antibodies (cat. no. NB810-82278; Novus Biologicals LLC, Littleton, CO, USA) were used. The percentage of apoptotic cells and the differentiation marker of cell surface expression were analyzed using Guava 1.0 software (Guava Technologies, Inc., Hayward, CA, USA).

Reverse transcription-quantitative polymerase chain reaction $(R T-q P C R)$. Total RNA was isolated with TRIzol, and complementary DNA was synthesized using TaKaRa RNA PCR kit (Takara Bio, Inc.) according to the manufacturer's protocol. The sequences of the PCR primers used in the amplification of the target genes are shown in Table I. RT-qPCR was performed with the double-stranded DNA dye SYBR Green PCR core reagents using the ABI ViiA 7 system (PerkinElmer, Inc., Waltham, MA, USA). Thermal cycler conditions were 
A

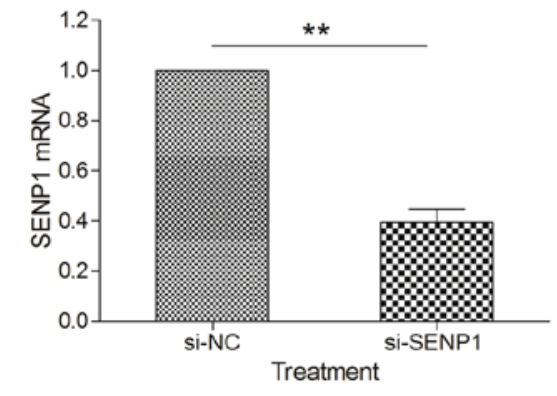

B

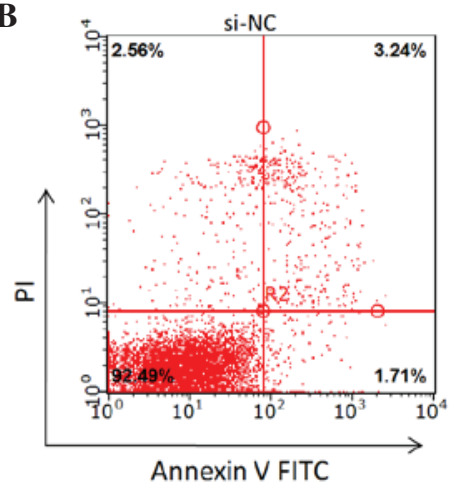

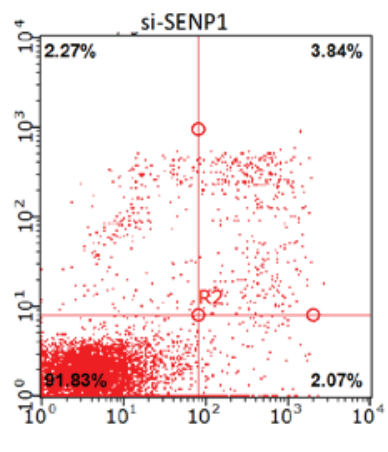

C
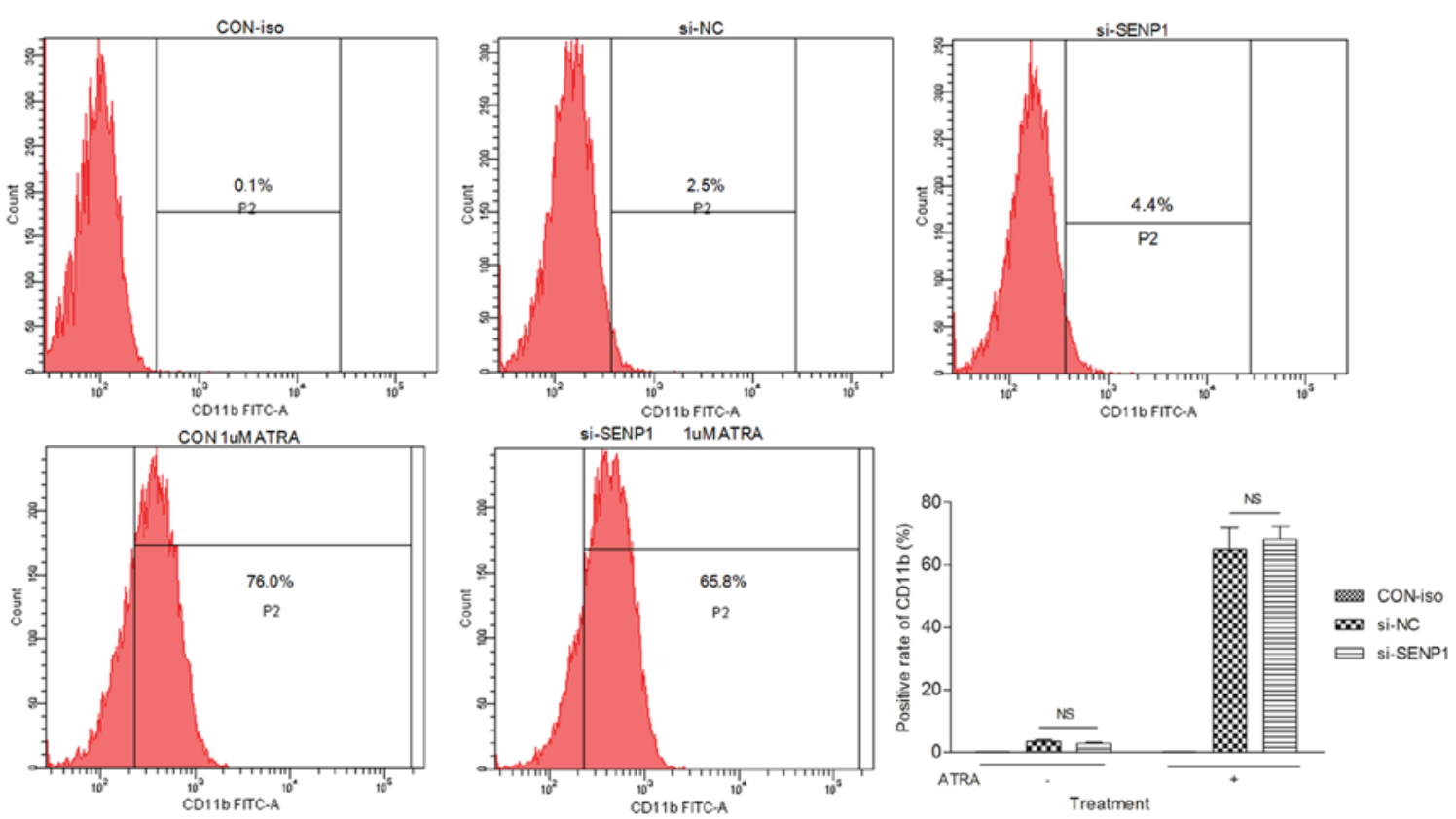

Figure 1. SENP1 deficiency has no effect on the spontaneous apoptosis or differentiation of NB4 cells. (A) mRNA expression level of SENP1 in cells transfected with si-SENP1 and cells transfected with si-NC. (B) Spontaneous apoptosis of NB4 cells transfected with si-SENP1 and si-NC. (C) Positive expression rate of CD11b in NB4 cells induced by ATRA for $72 \mathrm{~h} .{ }^{* *} \mathrm{P}<0.01, t$-test. SENP1, small ubiquitin-like modifier/sentrin-specific protease 1; mRNA, messenger RNA; NC, nonspecific control; si, small interfering; PI, propidium iodide; FITC, fluorescein isothiocyanate; CD, cluster of differentiation; ATRA, all-trans retinoic acid; CON, control; iso, isotype; NS, not significant.

$95^{\circ} \mathrm{C}$ for $30 \mathrm{sec}$, and 40 cycles of $95^{\circ} \mathrm{C}$ for $5 \mathrm{sec}$ and $60^{\circ} \mathrm{C}$ for $30 \mathrm{sec}$. Relative gene expression was determined by the delta delta $\mathrm{Cq}$ method (Applied Biosystems; Thermo Fisher Scientific, Inc.), with $\beta$-actin as the endogenous control using the Applied Biosystems ViiA ${ }^{\mathrm{TM}} 7$ Real-Time PCR system (Applied Biosystems; Thermo Fisher Scientific, Inc.) (16). Three independent experiments were performed, and the standard deviations (SDs) representing experimental errors were calculated. All data were analyzed using GraphPad Prism 5 software (GraphPad Software, Inc., La Jolla, CA, USA).

Immunoprecipitation. Treated cells were lysed with lysis buffer, and immunoprecipitation using anti-XBP1 and anti-SUMO-1 antibodies was performed as previously reported $(33,34)$. Briefly, cell lysates were centrifuged at $10,800 \mathrm{x} g$ for $15 \mathrm{~min}$ at $4^{\circ} \mathrm{C}$, and the supernatant was collected. Protein concentrations were determined by means of Lowry protein assay. Equal amounts of protein samples $(1 \mathrm{mg})$ were incubated with $2 \mu \mathrm{g}$ antibody for $3 \mathrm{~h}$ at $4^{\circ} \mathrm{C}$, followed by addition of pre-equilibrated Protein A/G PLUS-Agarose beads $(20 \mu \mathrm{l})$ and incubation overnight. The immunoprecipitates were washed four times with lysis buffer, and the bound proteins were boiled in $15 \mu \mathrm{l} 2 \mathrm{X}$ sodium dodecyl sulfate (SDS) sample buffer, eluted and resolved on 10\% SDS-polyacrylamide gel electrophoresis. The proteins were transferred onto a polyvinylidene fluoride membrane and probed with horseradish peroxidase (HRP)-phytohemagglutinin-L (Thermo Fisher Scientific, Inc.) and HRP-concanavalin A lectin (Abnova), and then detected using an enhanced chemiluminescence kit (Pierce Biotechnology, Inc., Rockford, IL, USA).

Statistical analyses. The data were presented as the mean $\pm \mathrm{SD}$. Statistical analysis was performed using GraphPad Prism 5 software. The paired $t$-test was used to compare the difference between two different groups. $\mathrm{P}<0.05$ was considered to indicate a statistically significant difference.

\section{Results}

SENPI deficiency has no effect on the spontaneous apoptosis or differentiation of NB4 cells. The fact that SENP1 was overexpressed in several neoplastic tissues (14-16) raised the 
A
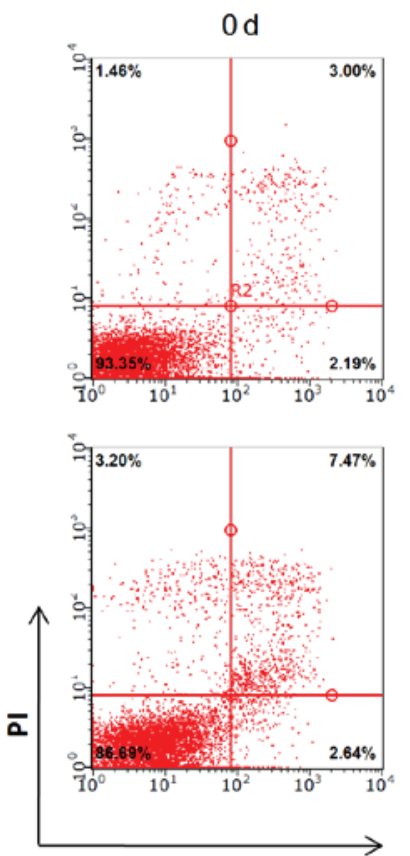

Annexin V-FITC
$1 d$
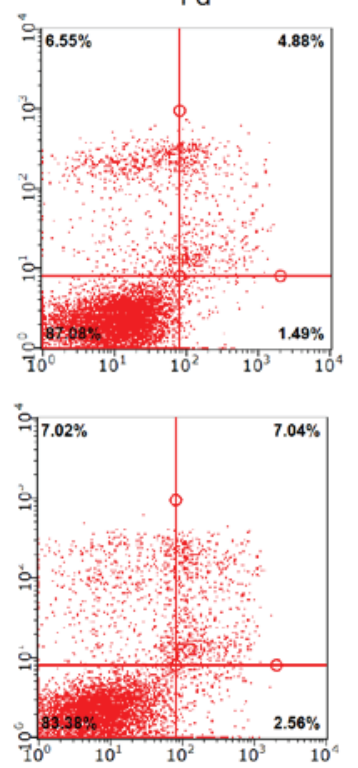
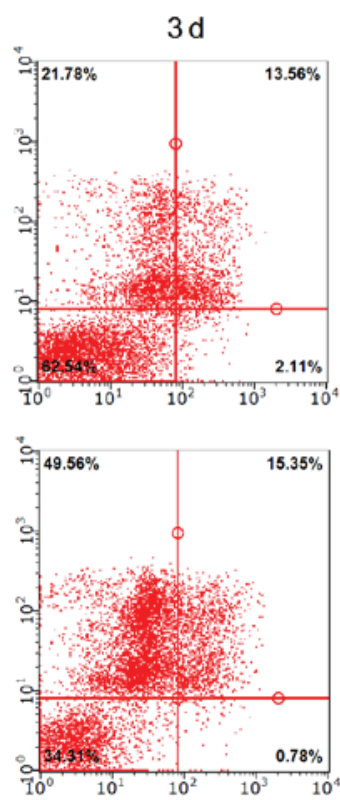

$\mathrm{As}_{2} \mathrm{O}_{3}(1 \mu \mathrm{M})$

si-NC

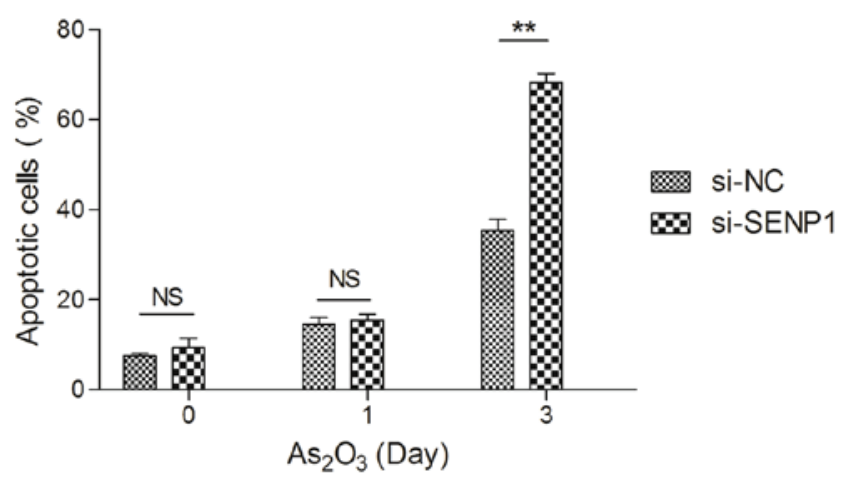

Figure 2. SENP1 deficiency promotes $\mathrm{As}_{2} \mathrm{O}_{3}$-induced NB4 cell apoptosis. (A) Apoptosis of the si-NC and si-SENP1 NB4 cells was analyzed by flow cytometry. (B) The number of apoptotic si-SENP1 cells was significantly higher than that of the si-NC cells, following treatment with $\mathrm{As}_{2} \mathrm{O}_{3}$ for $3 \mathrm{~d}^{* *} \mathrm{P}<0.01, t$-test. $\mathrm{SENP} 1$, small ubiquitin-like modifier/sentrin-specific protease 1; NC, nonspecific control; si, small interfering; PI, propidium iodide; FITC, fluorescein isothiocyanate; NS, not significant; $\mathrm{As}_{2} \mathrm{O}_{3}$, arsenic trioxide; d, day.

question whether SENP1 plays any role in the pathogenesis of APL. Thus, a SENP1-knockdown NB4 cell line (si-SENP1) was generated by stably transfecting SENP1 siRNA into NB4 cells. Compared with the NB4 cells transfected with NC scrambled siRNA (si-NC), the messenger RNA (mRNA) expression of SENP1 was significantly downregulated to $\sim 45 \%$ in si-SENP1 NB4 cells (Fig. 1A). A series of flow cytometry assays were performed to explore whether SENP1 deficiency would promote spontaneous apoptosis and differentiation in NB4 cells. Firstly, the percentage of apoptotic si-NC and si-SENP1 NB4 cells was examined by flow cytometry following annexin V-FITC and propidium iodide (PI) staining. As shown in Fig. 1B, knockdown of SENP1 had no effect on the spontaneous apoptosis of NB4 cells compared with si-NC cells. Next, the effects of SENP1 deficiency on NB4 cell differentiation were examined by detecting the expression levels of a differentiation marker, $\mathrm{CD} 11 \mathrm{~b}$. The results from cytometry revealed no difference in the expression of CD11b between si-NC and si-SENP1 NB4 cells, even after treatment with $1 \mu \mathrm{M}$ ATRA (a differentiation inducing agent) for $24 \mathrm{~h}$ (Fig. 1C). These results suggested that the downregulation of SENP1 has no effect on the spontaneous apoptosis or differentiation of NB4 cells.

SENP1 deficiency promotes $\mathrm{As}_{2} \mathrm{O}_{3}$-induced $\mathrm{NB} 4$ cell apoptosis. $\mathrm{As}_{2} \mathrm{O}_{3}$ has been successfully used in the treatment of APL $(7,35,36)$, and therapeutic doses of $\mathrm{As}_{2} \mathrm{O}_{3}$ could effectively induce complete molecular remission in vivo and trigger the apoptotic death of APL cells (37). Thus, we sought to investigate if the knockdown of SENP1 affects $\mathrm{As}_{2} \mathrm{O}_{3}$-induced apoptosis in NB4 cells. Therefore, normal and SENP1 knocked down NB4 cells treated with $\mathrm{As}_{2} \mathrm{O}_{3}$ were collected and subjected to flow cytometry assay upon annexin V-FITC and PI staining. As shown in Fig. 2A, after treatment with $\mathrm{As}_{2} \mathrm{O}_{3}$ for 3 days, the apoptotic cells in the si-NC NB4 group only increased by 2.90 -fold (from $12.92 \pm 1.00$ to $37.00 \pm 2.00 \%$ ), while in the si-SENP1 NB4 group, the apoptotic cells increased by $\leq 4.00$-fold (from $16.62 \pm 1.00$ to $66.00 \pm 3.00 \%$ ). The total number of apoptotic 
A

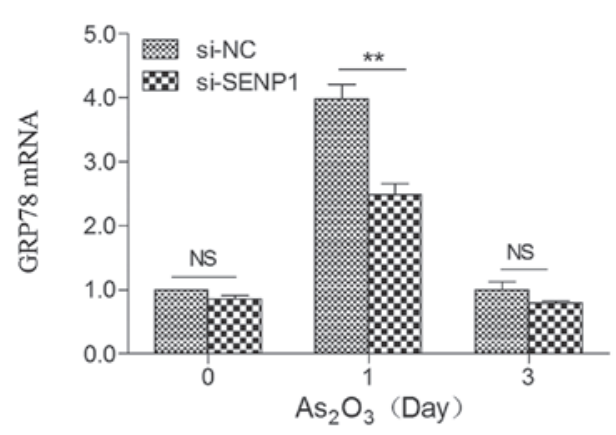

C

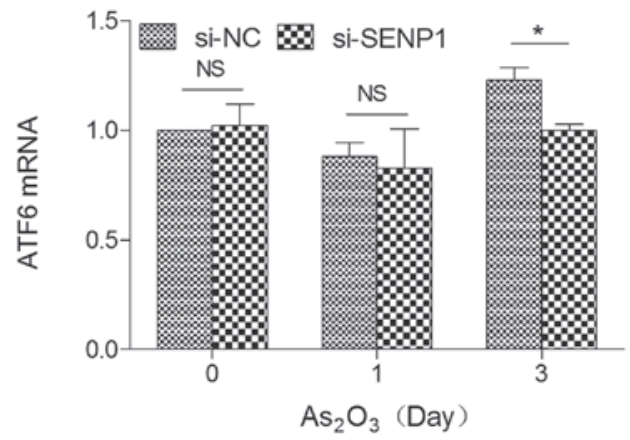

E

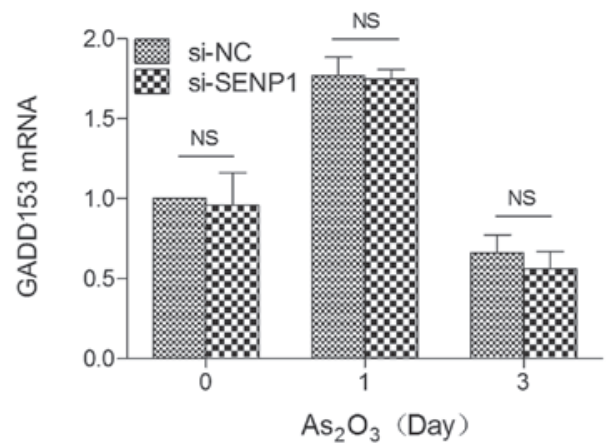

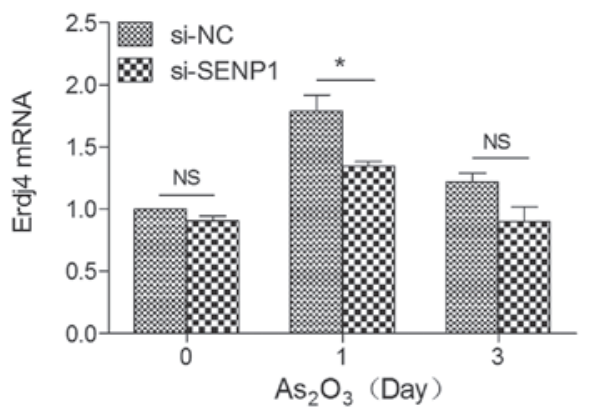

D

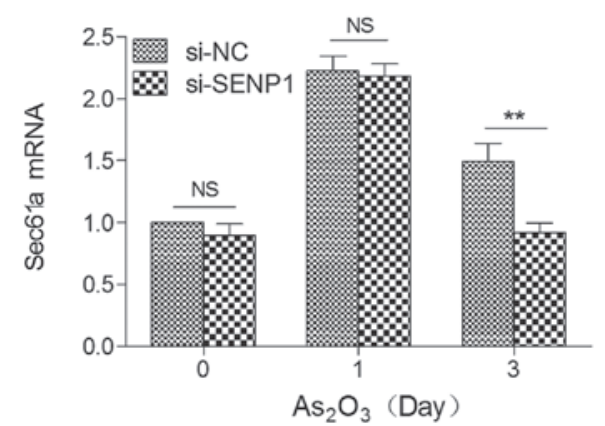

F

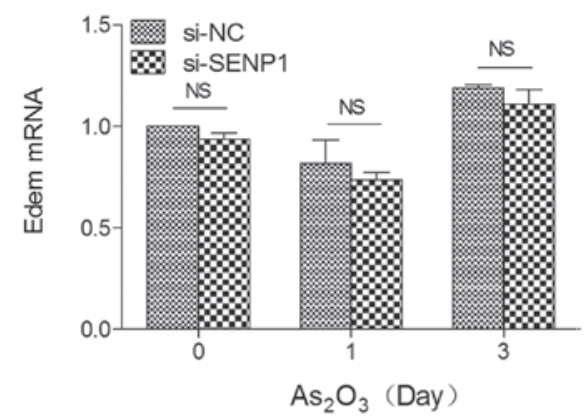

Figure 3. Expression levels of ER stress-related key markers (A) GRP78, (B) Erdj4, (C) ATF6, (D) Sec61a, (E) GADD153 and (F) Edem in SENP1-deficient cells treated with $\mathrm{As}_{2} \mathrm{O}_{3} \cdot{ }^{* *} \mathrm{P}<0.01 ;{ }^{*} \mathrm{P}<0.05, t$-test. SENP1, small ubiquitin-like modifier/sentrin-specific protease 1; GADD153, growth arrest and DNA damage inducible protein 153; ATF6, activating transcription factor 6; GRP78, 78 kDa glucose-regulated protein; ErdJ4, ER-localized DnaJ 4; Edem, ER degradation enhancer, mannosidase; NC, nonspecific control; si, small interfering; NS, not significant; $\mathrm{As}_{2} \mathrm{O}_{3}$, arsenic trioxide; mRNA, messenger RNA; ER, endoplasmic reticulum.

cells was $\sim 30 \%$ in si-SENP1 cells compared with that in si-NC cells (Fig. 2B), suggesting that SENP1 is essential for $\mathrm{NB} 4$ cell survival during treatment with $\mathrm{As}_{2} \mathrm{O}_{3}$.

SENP1 regulates the expression of XBP1 target genes in the ER stress-mediated apoptotic pathway. Numerous studies have revealed that $\mathrm{As}_{2} \mathrm{O}_{3}$ induces cell apoptosis through the ER stress pathway $(28,29,31)$. Thus, we assumed that $\mathrm{As}_{2} \mathrm{O}_{3}$-induced apoptosis may also accompany ER stress. Several key players, including CCAAT-enhancer-binding protein homologous protein [also known as growth arrest and DNA damage inducible protein 153 (GADD153)], activating transcription factor 6 (ATF6) and $78 \mathrm{kDa}$ glucose-regulated protein (GRP78), as well as XBP1 target genes, including ER-localized DnaJ 4 (Erdj4), Sec61a and ER degradation enhancer, mannosidase (Edem), are common markers that reflect the unfolded protein response during ER stress $(38,39)$. Therefore, to investigate the effects of SENP1 on the ER stress-mediated apoptotic pathway, the mRNA expression levels of the above proteins were detected by RT-qPCR in si-NC and si-SENP1 NB4 cells subsequent to treatment with $\mathrm{As}_{2} \mathrm{O}_{3}$ for different time periods. As shown in Fig. 3, the mRNA expression levels of these markers were highly increased by $~ 4.00$-fold (GRP78), 1.77-fold (GADD153), 1.80-fold (Erdj4) and 1.80-fold (Sec61a) in si-NC cells after $\mathrm{As}_{2} \mathrm{O}_{3}$ treatment for 1 day, but no effect on ATF6 or Edem (Fig. 3C and F) were observed, and upregulation was also observed in si-SENP1 NB4 cells, which revealed that $\mathrm{As}_{2} \mathrm{O}_{3}$ induced NB4 cell apoptosis through the ER stress-mediated apoptotic pathway. Additionally, among the XBP1 target genes, the mRNA expression levels of Erdj4 and Sec61a were significantly reduced by knockdown of SENP1 following $\mathrm{As}_{2} \mathrm{O}_{3}$ treatment in si-SENP1 NB4 cells (Fig. 3B and D).

SENP1 deficiency upregulates XBPI SUMOylation in si-SENP1 NB4 cells. Since the mRNA expression levels of XBP1 target genes, including Erdj4 and Sec61a, were significantly reduced in si-SENP1 NB4 cells upon $\mathrm{As}_{2} \mathrm{O}_{3}$ treatment, the present study next sought to explore whether XBP1 could be SUMOylated in si-SENP1 NB4 cells. As shown in Fig. 4, 


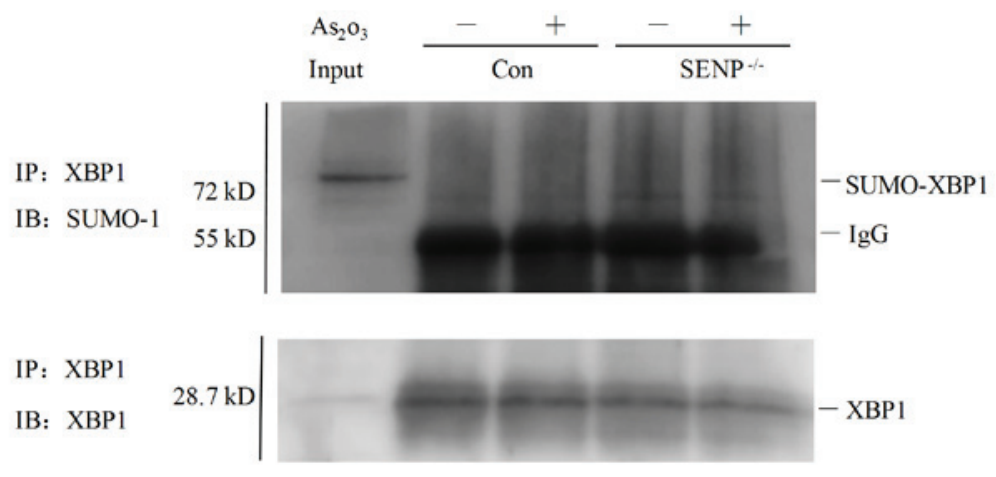

Figure 4. SENP1 deficiency upregulates XBP1 SUMOylation in NB4 si-NC (lanes 2 and 3) and si-SENP1 (lanse 4 and 5) cells treated with (lanes 3 and 5) or without (lanes 2 and 4) $\mathrm{As}_{2} \mathrm{O}_{3}$. SENP1, SUMO/sentrin-specific protease 1; SUMO, small ubiquitin-like modifier; XBP1, X-box binding protein 1; Con, control; IgG, immunoglobulin; IP, immunoprecipitation; IB, immunoblotting; $\mathrm{As}_{2} \mathrm{O}_{3}$, arsenic trioxide; si, small interfering.

in contrast to si-NC cells (Fig. 4, lanes 2 and 3), XBP1 was partly SUMOylated following immunoprecipitation with an anti-SUMO-1 antibody in si-SENP1 NB4 cells (Fig. 4, lanes 4 and 5). The input sample for immunoprecipitation was directly loaded to reveal the appropriate location of the protein bands of interest (Fig. 4, lane 1). These findings suggested that SENP1 deficiency may downregulate XBP1 transactivation by increasing XBP1 SUMOylation.

\section{Discussion}

APL is characterized by a specific $t(15 ; 17)$ chromosomal translocation that yields the PML/RARA fusion gene (3). It has been reported that $>97 \%$ of APL patients have the $t(15 ; 17)$ translocation, and several rare variant translocations observed in the remaining APL patients always involve $\operatorname{RAR} \alpha(3,40)$. $\mathrm{As}_{2} \mathrm{O}_{3}$ is an effective treatment for this disease, since it could induce SUMO-dependent ubiquitin-mediated proteasomal degradation of PML-RAR $\alpha$ (41). However, knockdown of SENP1 had no effect on the SUMOylation of PML-RAR $\alpha$ in NB4 cells, even after NB4 cells were treated with $1 \mu \mathrm{M} \mathrm{As}{ }_{2} \mathrm{O}_{3}$ (data not shown), suggesting the possibility that other members of the SENP family may be involved in regulating the level of SUMOylated PML-RAR $\alpha$, which remains to be further investigated. It has been reported that knockdown of SENP1 could promote drug-induced cell apoptosis in MEF and HEK 293T cells, as well as lung cancer and Burkitt lymphoma cells (17-19). However, our results revealed that downregulation of SENP1 had no effect on the spontaneous apoptosis or differentiation of NB4 cells (Fig. 1). Furthermore, it was observed that downregulation of SENP1 had no impact on drug-induced apoptosis or differentiation in NB4 cells (Fig. 1).

The metabolism of $\mathrm{As}_{2} \mathrm{O}_{3}$ in APL cells is complex (42). Production of intracellular methylated metabolites and epigenetic changes of DNA methylation during $\mathrm{As}_{2} \mathrm{O}_{3}$ metabolism may contribute to the therapeutic efficacy of $\mathrm{As}_{2} \mathrm{O}_{3}$ in APL (43). The signaling cascades and transcription factors related to $\mathrm{As}_{2} \mathrm{O}_{3}$-induced apoptosis were caused by reactive oxygen species formation $(44,45)$, resulting in the stimulation of apoptosis in leukemia cells. In contrast to the observation that inhibition of phosphoinositide 3-kinase (PI3K)/Akt could increase $\mathrm{As}_{2} \mathrm{O}_{3}$-induced apoptosis of APL cells $(46,47)$, in the present study, it was observed that downregulation of SENP1 could promote $\mathrm{As}_{2} \mathrm{O}_{3}$-induced NB4 cell apoptosis, suggesting that there may be pathways other than PI3K/Akt contributing to the effect of SENP1 on $\mathrm{As}_{2} \mathrm{O}_{3}$-treated APL cells. Numerous studies have demonstrated that $\mathrm{As}_{2} \mathrm{O}_{3}$ could induce cell apoptosis through the ER stress pathway $(28,29,31,48)$. Consistently, in our study, the upregulation of key markers of the ER stress-mediated apoptotic pathway in si-SENP1 NB4 cells indicated that $\mathrm{As}_{2} \mathrm{O}_{3}$ could induce NB4 cell apoptosis through the ER stress-mediated apoptotic pathway. Notably, the high ER stress induced by $\mathrm{As}_{2} \mathrm{O}_{3}$ treatment at day 1 in the present study led to significant cell apoptosis at day 3 , which may be explained by the sustained effect of $\mathrm{As}_{2} \mathrm{O}_{3}$-induced apoptosis. SUMOylation is a dynamic process that is reversed by proteins of the SENP family, which can be catalyzed by SUMO-specific activating (E1), conjugating (E2) and ligating (E3) enzymes (49). The modification of proteins with SUMO plays pivotal roles in modulating the activation, function and subcellular localization of these proteins (50). The transcription factor XBP1 is a key component of the ER stress response and a critical transcription factor that drives the transcription of various genes $(51,52)$. Additionally, XBP1 can be activated in MEF and HEK 293T cells via the de-SUMOylation function of SENP1 (18). Therefore, it would be reasonable to assume the existence of an intrinsic mechanism by which the downregulation of SENP1 affects cell apoptosis in the treatment of APL with $\mathrm{As}_{2} \mathrm{O}_{3}$. Our data suggested that SENP1 regulated XBP1 transactivation by regulating the expression of XBP1 target genes, and that SENP1 may play a specific role in regulating XBP1 activity during $\mathrm{As}_{2} \mathrm{O}_{3}$-induced apoptosis. Of note, SENP1 downregulation also reduced the expression of the transcription factor GRP78, which was involved in the ER stress response after $\mathrm{As}_{2} \mathrm{O}_{3}$ treatment for 1 day (Fig. 3C), suggesting that SENP1 and its downstream signaling pathway may affect other transcription factors involved in ER stress.

Taken together, our study provided the first evidence for $\mathrm{As}_{2} \mathrm{O}_{3}$-induced NB4 cell apoptosis through the ER stress-mediated apoptotic pathway, and demonstrated that SENP1 downregulation promoted $\mathrm{As}_{2} \mathrm{O}_{3}$-induced NB4 cell apoptosis. The knockdown of SENP1 also increased the levels of accumulated SUMOylated XBP1, which was 
accompanied by downregulation of the mRNA expression and transcriptional activity of XBP1 target genes, which were involved in ER stress response and closely linked to the apoptosis of NB4 cells. Our data also provided insight into potential therapeutic targets for APL treatment via manipulating XBP1 signaling during ER stress by targeting SENP1.

\section{Acknowledgements}

The present study was supported by Shanghai Health Bureau of Scientific Research Projects (Shanghai, China; grant no. 20124Y110), the Scientific Research Foundation of XinHua Hospital Group (Shanghai, China; grant no. 12XJ22005) and the National Natural Science Foundation of China (Beijing, China; grant nos. 81401572 and 81201450, awarded to Q.C.).

\section{References}

1. Kömür M, Erbey F, Bayram I and Tanyeli A: Incidence and prognostic importance of molecular genetic defects in children with acute myeloblastic leukemia. Asian Pac J Cancer Prev 11: 1393-1395, 2010

2. Gilliland DG: Molecular genetics of human leukemia. Leukemia 12 (Suppl 1): S7-S12, 1998.

3. Rowley JD, Golomb HM and Dougherty C: $15-17$ translocation, a consistent chromosome change in acute promyelocytic leukemia. Lancet 1: 549-50, 1977.

4. Melnick A and Licht JD: Deconstructing a disease: RARalpha, its fusion partners and their roles in the pathogenesis of acute promyelocytic leukemia. Blood 93: 3167-3215, 1999.

5. Burnett AK, Grimwade D, Solomon E, Wheatley K and Goldstone AH: Presenting white blood cell count and kinetics of molecular remission predict prognosis in acute promyelocytic leukemia treated with all-trans retinoic acid: Result of the Randomized MRC Trial. Blood 93: 4131-4143, 1999.

6. Fenaux P, Chastang C, Chevret S, Sanz M, Dombret H, Archimbaud E, Fey M, Rayon C, Huguet F, Sotto JJ, et al: A randomized comparison of all transretinoic acid (ATRA) followed by chemotherapy and ATRA plus chemotherapy and the role of maintenance therapy in newly diagnosed acute promyelocytic leukemia. The European APL Group. Blood 94: 1192-1200, 1999.

7. Chen GQ, Zhu J, Shi XG, Ni JH, Zhong HJ, Si GY, Jin XL, Tang W, $\mathrm{Li}$ XS, Xong SM, et al: In vitro studies on cellular and molecular mechanisms of arsenic trioxide $\left(\mathrm{As}_{2} \mathrm{O}_{3}\right)$ in the treatment of acute promyelocytic leukemia: As2O3 induces NB4 cell apoptosis with downregulation of $\mathrm{Bcl}-2$ expression and modulation of PML-RAR alpha/PML proteins. Blood 88: 1052-1061, 1996.

8. Lam MS and Ignoffo RJ: Arsenic trioxide for the treatment of acute promyelocytic leukemia. Cancer Pract 9: 155-157, 2001.

9. Bawa-Khalfe T and Yeh ET: SUMO losing balance: SUMO proteases disrupt SUMO homeostasis to facilitate cancer development and progression. Genes Cancer 1: 748-752, 2010.

10. Cheng J, Kang X, Zhang S and Yeh ET: SUMO-specific protease 1 is essential for stabilization of HIFlalpha during hypoxia. Cell 131: 584-595, 2007.

11. Yu L, Ji W, Zhang H, Renda MJ, He Y, Lin S, Cheng EC, Chen H, Krause DS and Min W: SENP1-mediated GATA1 deSUMOylation is critical for definitive erythropoiesis. J Exp Med 207: 1183-1195, 2010.

12. Liu B, Wang T, Mei W, Li D, Cai R, Zuo Y and Cheng JK: Small ubiquitin-like modifier (SUMO) protein-specific protease 1 de-SUMOylates Sharp-1 protein and controls adipocyte differentiation. J Biol Chem 289: 22358-22364, 2014

13. Gu J, Fan Y, Liu X, Zhou L, Cheng J, Cai R and Xue S: SENP1 protects against myocardial ischaemia/reperfusion injury via a HIF1 $\alpha$-dependent pathway. Cardiovasc Res 104: 83-92, 2014.

14. Bawa-Khalfe T, Cheng J, Lin SH, Ittmann MM and Yeh ET: SENP1 induces prostatic intraepithelial neoplasia through multiple mechanisms. J Biol Chem 285: 25859-25866, 2010.

15. Xu Y, Li J, Zuo Y, Deng J, Wang LS and Cheng GQ: SUMO-specific protease 1 regulates the in vitro and in vivo growth of colon cancer cells with the upregulated expression of CDK inhibitors. Cancer Lett 309: 78-84, 2011.
16. Ma C, Wu B, Huang X, Yuan Z, Nong K, Dong B, Bai Y, Zhu $\mathrm{H}$, Wang W and Ai K: SUMO-specific protease 1 regulates pancreatic cancer cell proliferation and invasion by targeting MMP-9. Tumour Biol 35: 12729-12735, 2014.

17. Wang RT, Zhi XY, Zhang Y and Zhang J: Inhibition of SENP1 induces radiosensitization in lung cancer cells. Exp Ther Med 6 : 1054-1058, 2013.

18. Jiang Z, Fan Q, Zhang Z, Zou Y, Cai R, Wang Q, Zuo Y and Cheng J: SENP1 deficiency promotes ER stress-induced apoptosis by increasing XBP1 SUMOylation. Cell Cycle 11: 1118-1122, 2012

19. Huang BB, Gao QM, Liang W, Xiu B, Zhang WJ and Liang AB: Downregulation of SENP1 expression increases apoptosis of Burkitt lymphoma cells. Asian Pac J Cancer Prev 13: 2045-2049, 2012.

20. Sharma P, Murillas R, Zhang H and Kuehn MR: N4BP1 is a newly identified nucleolar protein that undergoes SUMO-regulated polyubiquitylation and proteasomal turnover at promyelocytic leukemia nuclear bodies. J Cell Sci 123: 1227-1234, 2010.

21. Ohbayashi N, Kawakami S, Muromoto R, Togi S, Ikeda O, Kamitani S, Sekine Y, Honjoh T and Matsuda T: The IL-6 family of cytokines modulates STAT3 activation by desumoylation of PML through SENP1 induction. Biochem Biophys Res Commun 371: 823-828, 2008.

22. Kastner P, Perez A, Lutz Y, Rochette-Egly C, Gaub MP, Durand B, Lanotte M, Berger R and Chambon P: Structure, localization and transcriptional properties of two classes of retinoic acid receptor alpha fusion proteins in acute promyelocytic leukemia (APL): Structural similarities with a new family of oncoproteins. EMBO J 11: 629-642, 1992.

23. Mollereau B, Manié S and Napoletano F: Getting the better of ER stress. J Cell Commun Signal 8: 311-321, 2014.

24. Gorman AM, Healy SJ, Jäger R and Samali A: Stress management at the ER: Regulators of ER stress-induced apoptosis. Pharmacol Ther 134: 306-316, 2012.

25. Mathur A, Abd Elmageed ZY, Liu X, Kostochka ML, Zhang H, Abdel-Mageed AB and Mondal D: Subverting ER-stress towards apoptosis by nelfinavir and curcumin coexposure augments docetaxel efficacy in castration resistant prostate cancer cells. PLoS One 9: e103109, 2014.

26. Kondo S, Hino SI, Saito A, Kanemoto S, Kawasaki N, Asada R, Izumi S, Iwamoto H, Oki M, Miyagi $\mathrm{H}$, et al: Activation of OASIS family, ER stress transducers, is dependent on its stabilization. Cell Death Differ 19: 1939-1949, 2012.

27. Qin L, Wang Z, Tao L and Wang Y: ER stress negatively regulates AKT/TSC/mTOR pathway to enhance autophagy. Autophagy 6: 239-247, 2010

28. Chiu HW, Tseng YC, Hsu YH, Lin YF, Foo NP, Guo HR and Wang YJ: Arsenic trioxide induces programmed cell death through stimulation of ER stress and inhibition of the ubiquitin-proteasome system in human sarcoma cells. Cancer Lett 356: 762-772, 2015.

29. Li K, Zhang L, Xiang X, Gong S, Ma L, Xu L, Wang G, Liu Y, Ji X, Liu S, et al: Arsenic trioxide alleviates airway hyperresponsiveness and promotes apoptosis of $\mathrm{CD}_{4}+\mathrm{T}$ lymphocytes: Evidence for involvement of the ER stress-CHOP pathway. Ir J Med Sci 182: 573-583, 2013.

30. Doudican NA, Wen SY, Mazumder A and Orlow SJ: Sulforaphane synergistically enhances the cytotoxicity of arsenic trioxide in multiple myeloma cells via stress-mediated pathways. Oncol Rep 28: 1851-1858, 2012.

31. Zhang H, Duncan G, Wang L, Liu P, Cui H, Reddan JR, Yang BF and Wormstone IM: Arsenic trioxide initiates ER stress responses, perturbs calcium signalling and promotes apoptosis in human lens epithelial cells. Exp Eye Res 85: 825-835, 2007.

32. Fan YH, Chen M, Meng J, Yu L, Tu Y, Wan L, Fang K and Zhu W: Arsenic trioxide and resveratrol show synergistic anti-leukemia activity and neutralized cardiotoxicity. PLoS One 9: e105890, 2014

33. Liu M, Yang Y, Wang C, Sun L, Mei C, Yao W, Liu Y, Shi Y, Qiu S, Fan J, et al: The effect of epidermal growth factor receptor variant III on glioma cell migration by stimulating ERK phosphorylation through the focal adhesion kinase signaling pathway. Arch Biochem Biophys 502: 89-95, 2010.

34. Wang C, Yang Y, Yang Z, Liu M, Li Z, Sun L, Mei C, Chen H, Chen L, Wang L and Zha X: EGF-mediated migration signaling activated by $\mathrm{N}$-acetylglucosaminyltransferase-V via receptor protein tyrosine phosphatase kappa. Arch Biochem Biophys 486: 64-72, 2009. 
35. Ghaffari SH, Bashash D, Dizaji MZ, Ghavamzadeh A and Alimoghaddam K: Alteration in miRNA gene expression pattern in acute promyelocytic leukemia cell induced by arsenic trioxide: A possible mechanism to explain arsenic multi-target action. Tumour Biol 33: 157-172, 2012.

36. Ghaffari SH, Momeny M,Bashash D, Mirzaei R, Ghavamzadeh A and Alimoghaddam K: Cytotoxic effect of arsenic trioxide on acute promyelocytic leukemia cells through suppression of NFk $\beta$-dependent induction of hTERT due to downregulation of Pin1 transcription. Hematology 17: 198-206, 2012.

37. Zhao XY, Yang S, Chen YR, Li PC, Dou MM and Zhang J: Resveratrol and arsenic trioxide act synergistically to kill tumor cells in vitro and in vivo. PLoS One 9: e98925, 2014

38. So AY, de la Fuente E, Walter P, Shuman M and Bernales S: The unfolded protein response during prostate cancer development. Cancer Metastasis Rev 28: 219-223, 2009.

39. Yamamoto $\mathrm{K}$, Tashiro $\mathrm{E}$ and Imoto $\mathrm{M}$ : Quinotrierixin inhibited ER stress-induced XBP1 mRNA splicing through inhibition of protein synthesis. Biosci Biotechnol Biochem 75: 284-288, 2011.

40. Nasr R, Lallemand-Breitenbach V, Zhu J, Guillemin MC and de Thé H: Therapy-induced PML/RARA proteolysis and acute promyelocytic leukemia cure. Clin Cancer Res 15: 6321-6326, 2009.

41. Geoffroy MC, Jaffray EG, Walker KJ and Hay RT: Arsenic-induced SUMO-dependent recruitment of RNF4 into PML nuclear bodies. Mol Biol Cell 21: 4227-4239, 2010.

42. Chen GQ, Shi XG, Tang W, Xiong SM, Zhu J, Cai X, Han ZG, Ni JH, Shi GY, Jia PM, et al: Use of arsenic trioxide (As2O3) in the treatment of acute promyelocytic leukemia (APL): I. As2O3 exerts dose-dependent dual effects on APL cells. Blood 89 3345-3353, 1997.

43. Khaleghian A, Ghaffari SH, Ahmadian S, Alimoghaddam K and Ghavamzadeh A: Metabolism of arsenic trioxide in acute promyelocytic leukemia cells. J Cell Biochem 115: 1729-1739, 2014.
44. Sumi D, Shinkai Y and Kumagai Y: Signal transduction pathways and transcription factors triggered by arsenic trioxide in leukemia cells. Toxicol Appl Pharmacol 244: 385-392, 2010.

45. Wang J, Li L, Cang H, Shi G and Yi J: NADPH oxidase-derived reactive oxygen species are responsible for the high susceptibility to arsenic cytotoxicity in acute promyelocytic leukemia cells. Leuk Res 32: 429-436, 2008.

46. Tabellini G, Cappellini A, Tazzari PL, Falà F, Billi AM, Manzoli L, Cocco L and Martelli AM: Phosphoinositide 3-kinase/Akt involvement in arsenic trioxide resistance of human leukemia cells. J Cell Physiol 202: 623-634, 2005.

47. Tabellini G, Tazzari PL, Bortul R, Evangelisti C, Billi AM, Grafone T, Martinelli G, Baccarani M and Martelli AM: Phosphoinositide 3-kinase/Akt inhibition increases arsenic trioxide-induced apoptosis of acute promyelocytic and T-cell leukaemias. Br J Haematol 130: 716-725, 2005.

48. Binet F, Chiasson S and Girard D: Evidence that endoplasmic reticulum (ER) stress and caspase-4 activation occur in human neutrophils. Biochem Biophys Res Commun 391: 18-23, 2010.

49. Wang Y and Dasso M: SUMOylation and deSUMOylation at a glance. J Cell Sci 122: 4249-4252, 2009.

50. Verger A, Perdomo J and Crossley M: Modification with SUMO. A role in transcriptional regulation. EMBO Rep 4: 137-142, 2003

51. Quentin T, Steinmetz M, Poppe A and Thoms S: Metformin differentially activates ER stress signaling pathways without inducing apoptosis. Dis Model Mech 5: 259-269, 2012.

52. Ibuki T, Yamasaki Y, Mizuguchi $\mathrm{H}$ and Sokabe M: Protective effects of XBP1 against oxygen and glucose deprivation/reoxygenation injury in rat primary hippocampal neurons. Neurosci Lett 518: 45-48, 2012. 